\title{
Arthroscopic-assisted Latissimus Dorsi Tendon Transfer for the Management of Irreparable Rotator Cuff Tears in Middle-aged Physically Active Patients
}

\author{
Tae Kang Lim ${ }^{\varpi}$, Kyu Hwan Bae \\ Department of Orthopedic Surgery, Eulji Hospital, Eulji University School of Medicine, Seoul, Korea
}

Background: Latissimus dorsi (LD) tendon transfer is used as a treatment option for massive irreparable posterosuperior rotator cuff tears, and recently, an arthroscopic-assisted technique was introduced. This study was undertaken to evaluate the clinical and radiological outcomes of arthroscopic-assisted LD tendon transfer for the management of irreparable rotator cuff tears in active middle-aged patients.

Methods: The records of five patients (two males) with irreparable tears involving the supraspinatus and infraspinatus tendons managed by arthroscopic-assisted LD tendon transfer were retrospectively reviewed. Clinical outcomes were assessed using the visual analogue scale (VAS) pain scale, American Shoulder and Elbow Surgeon's (ASES) scores, the University of California Los Angeles (UCLA) scale, and ranges of motion. Postoperative integrities of transferred tendon were evaluated by magnetic resonance imaging in 4 patients and by ultrasound in one.

Results: Mean patient age was 55 years (range, 48-61 years), and mean follow-up period was 20 months (range, 12.0-27.2 months). Mean VAS score significantly improved from $6.6 \pm 2.6$ preoperatively to $1.8 \pm 2.5$ postoperatively $(p=0.009)$, mean ASES score increased from $67.6 \pm 9.2$ to $84.6 \pm 15.1$, and mean UCLA score from $18.0 \pm 1.4$ to $28.8 \pm 8.5$ (all $p<0.001$ ). Postoperative imaging of the transferred LD tendon showed intact repair in 4 patients. The remaining patient experienced LD transfer rupture and a poor outcome.

Conclusions: Arthroscopic-assisted LD tendon transfer improved shoulder pain and function in patients with massive, irreparable rotator cuff tears, and may be an option for this condition, especially in physically active patients.

(Clin Shoulder Elbow 2019;22(1):9-15)

Key Words: Irreparable; Rotator cuff tear; Latissimus dorsi; Arthroscopic; Tendon transfer

\section{Introduction}

Massive irreparable posterosuperior rotator cuff tears are difficult to treat, especially in physically active patients. ${ }^{1)}$ Although repair can be attempted, it is associated with high retear rates and poor outcomes. Treatment options in the literature include debridement and biceps tenotomy, ${ }^{2)}$ partial repair, ${ }^{3)}$ repair with patch augmentation, ${ }^{4)}$ and muscle transfer, ${ }^{5)}$ and the recently introduced superior capsule reconstruction technique. ${ }^{6)}$
Latissimus dorsi (LD) tendon transfer was first described by Gerber $^{7}$ in 1992 and is an accepted viable treatment option. In 2013, the same authors reported the 10-year outcomes of their series and demonstrated the procedure was durable in terms of improving shoulder pain and function. ${ }^{5)}$ In 2015, Grimberg et al. ${ }^{8)}$ described an arthroscopic-assisted LD tendon transfer technique with claimed advantages that included the preservation of deltoid muscle and minimal invasiveness. Although this technique is technically demanding and carries risks of axillary

Received September 29, 2018. Revised November 21, 2018. Accepted December 2, 2018.

Correspondence to: Tae Kang Lim

Department of Orthopedic Surgery, Eulji Hospital, Eulji University School of Medicine, 68 Hangeulbiseok-ro, Nowon-gu, Seoul 01830, Korea Tel: +82-2-970-8036, Fax: +82-2-973-3024, E-mail: fromspace@daum.net, ORCID: https://orcid.org/0000-0001-8752-3987

IRB approval: Eulji Hospital, Eulji University School of Medicine (EMCS 2018-07-030).

Financial support: None. Conflict of interests: None. 
or radial nerve injuries, it has been shown to produce clinical outcomes similar to open techniques for massive rotator cuff tears. ${ }^{8,9)}$ However, few studies have been performed on arthroscopic-assisted LD tendon transfer and those that have been published included patients with widely different ages. Furthermore, we are unaware of any Korean sourced reports on the outcomes of this technique.

The purpose of this study was to evaluate clinical and radiographic outcomes of arthroscopic-assisted LD tendon transfer for management of irreparable rotator cuff tears. We hypothesized that this technique would provide good clinical and radiological outcomes in active middle-aged patients.

\section{Methods}

\section{Patient Selection}

We evaluated outcomes after arthroscopic-assisted LD tendon transfer performed by a single surgeon between 2012 and 2016. Indications for surgery were as follows; 1 ) symptomatic, massive rotator cuff tear involving supraspinatus and infraspinatus tendons, and/or a partial upper subscapularis tendon tear, 2) an irreparable tear onto the medial margin of the greater tuberosity footprint after release and mobilization of retracted tendons, 3) advanced muscle atrophy (grade $\geq 2$ by the Warner classification) and fatty infiltration (stage 3 or 4 by Goutallier's classification) of the supraspinatus and infraspinatus by preoperative magnetic resonance imaging (MRI), 4) no or mild arthritis of the shoulder joint on simple radiographs (Hamada stage 1, 2, or 3 ), and 5) a physically active patient aged $<65$ years. During the study period, 72 consecutive patients with symptomatic, massive rotator cuff tear were surgically treated; 38 reparable tears were treated by standard arthroscopic rotator cuff repair with or without augmentation and 29 irreparable tears with advanced arthritis (Hamada classification stage 4 or higher) in elderly patients ( $\geq 65$ years) were treated by reverse shoulder arthroplasty. The remaining 5 patients underwent arthroscopic-assisted LD tendon transfer and constituted the subjects of the present study. All arthroscopic-assisted LD tendon transfer candidates were counseled about possible treatment options by the treating surgeon and informed of the advantages and disadvantages of the technique. No patient that underwent this procedure was excluded from the analysis.

\section{Surgical Technique}

Surgeries were performed by a single shoulder surgeon (TKL) with the patient in the lateral decubitus position with the affected arm abducted at $70^{\circ}$ with longitudinal traction under general anesthesia. Using standard portals (anterior, posterior, lateral and posterolateral portals), an arthroscope was introduced into the glenohumeral joint and subacromial space. Initially, the routine aspects of rotator cuff repair procedures, such as diagnostic arthroscopy, biceps tenotomy or tenodesis, and partially torn subscapularis tendon repair were performed. Subacromial decompression and acromioplasty were then performed in the subacromial space. Suture anchors used for previous rotator cuff repair, if present, were removed from the greater tuberosity, and a bone bed was prepared with slight decortication and microfracture. Tear size was measured using a calibrated probe in millimeters mediolaterally and anteroposteriorly. A massive tear was defined as a tear exceeding $50 \mathrm{~mm}$ in length in any direction or complete tear of the supraspinatus and infraspinatus tendons (involving two tendons posterosuperiorly). Reparability of retracted rotator cuff tears was then evaluated using a grasper to determine how much coverage of the original footprint was possible. If torn tendons were retracted to the glenoid and only approximated to the mid-humeral head level, not up to the articular margin of the greater tuberosity, retracted tendons were released and mobilized. Anteriorly, the coracohumeral ligament was released, and any adhesions of the supraspinatus tendon to the rotator interval and capsule were thoroughly removed to improve cuff mobility. Posteriorly, the interval between the supraspinatus and infraspinatus was identified, and interval tissues were released from the scapular spine (the interval slide incontinuity ${ }^{10)}$ ) or sometimes, released completely through the interval. When torn tendons were not reduced to the articular margin of the greater tuberosity footprint at the completion of all releases both anteriorly and posteriorly the tear concerned was defined as irreparable. For such tears, we continued to perform
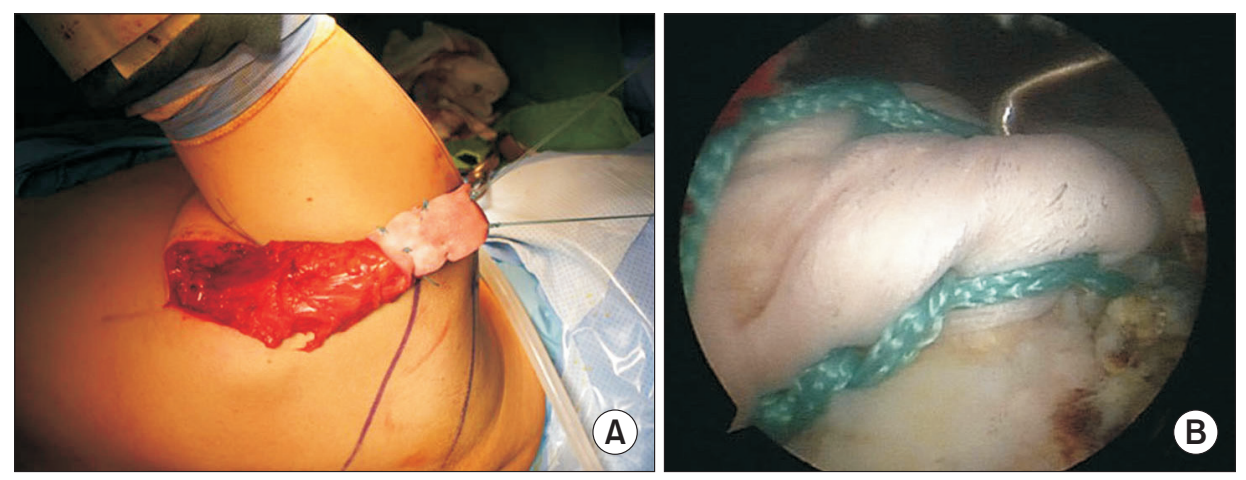

Fig. 1. (A) Intraoperative photograph of a 57-year-old male patient, left shoulder, showing the mobilized latissimus dorsi tendon detached from its origin on the proximal humeral shaft. The tendon was augmented with human dermal patch allograft (Megaderm; L\&C BIO, Seongnam, Korea). (B) Arthroscopid fixation of the latissimus dorsi tendon was completed. 
LD transfer and started with LD tendon harvesting. Briefly, a curvilinear incision was made along the lateral border of the scapula and posterior to the lateral profile of the LD tendon. After identifying the LD muscle and its insertion on the proximal humeral shaft, the insertion was sharply detached from the humerus. The arm was then further abducted and internally rotated to facilitate exposure of the tendon insertion, and the tendon was then mobilized and pulled until it reached the acromion anterior edge (Fig. 1A). When this was not possible, the tendon was released proximally to the musculotendinous junction while taking care not to damage the neurovascular bundle. Krackow stitches were then placed along both borders of the tendon using nonabsorbable sutures (No. 5 Ethibond; Ethicon, Somerville, NJ, USA). As the harvested LD tendon is thin and flat, it was augmented with use of human dermal patch allograft (Megaderm; L\&C BIO, Seongnam, Korea) in order to have a thicker and longer tendon. Next, we re-introduced an arthroscope into the subacromial space. Posteriorly, the interval between the deltoid and teres major was developed bluntly to facilitate tendon passage as confirmed by inserting a finger from the posterior incision and by visualization using an arthroscope in the subacromial space. The anterior and posterior suture limbs of the Krackow sutures of the LD tendon were then retrieved from the anterior portal, and the harvested tendon was passed into the subacromial space by pulling the sutures out of the anterior portal. The anterior border of the transferred tendon was then fixed to the anterior margin of the greater tuberosity footprint using two knotless anchors (4.5 mm, Bio-Swievelock; Arthrex, Naples, FL, USA [Fig. 1B]), and its medial and lateral borders were fixed to the greater tuberosity footprint in a double-row fashion using the conventional suture bridge technique. A total of 5 anchors were used to fix the transferred LD tendon. Mean surgical time was $202 \pm 17$ minutes), and mean anesthesia time was $250 \pm 14$ minutes). During the six weeks following surgery the arm is immobilized in $30^{\circ}$ of abduction and neutral rotation using abduction brace. Stretching exercises are started after brace removal, and strengthening exercises from 3 months postoperatively.

\section{Clinical and Radiographic Evaluations}

Each patient underwent a preoperative clinical evaluation the day before surgery by an independent observer and scheduled for regular follow-up visits at 2 weeks, 6 weeks, 3 months, 6 months, 1 year, and 2 years after surgery. Preoperative and postoperative clinical outcomes were assessed using the visual analogue scale (VAS) pain scale, American Shoulder and Elbow Surgeon's (ASES) scores, the University of California Los Angeles (UCLA) scale, and measured ranges of motion. Radiographic assessments included preoperative standard radiographs and MRI of the shoulder joint. At 6 months postoperatively, transferred LD tendon repair integrities were evaluated by MRI or ultrasound. All radiographic images were reviewed by the treating surgeon and an orthopedic resident.

\section{Statistical Analysis}

The paired t-test and Wilcoxon's signed-rank test were used to compare preoperative VAS, ASES, and UCLA scores and ranges of motion with those obtained at final follow-up. For all analyses, $p$-values of less than 0.05 were considered significant $(p<0.05)$.

\section{Results}

\section{Patients}

Mean age of the five patients was 55 years (range, 48-61 years). There were two males and right shoulders were affected in three patients. Two patients had a trauma history; one during ice hockey and the other by a slip-down while washing clothes. The three female patients were housewives and complained of shoulder pain and weakness during daily housework, especially difficulty in keeping their hands in space. One male patient worked in a market and his work involved heavy lifting. The other male patient was paraplegic as a result of spinal cord injury and was wheelchair-ridden. His shoulder was weight-bearing to move from bed to wheelchair, and he was a member of the national disabled basketball team. Therefore, all five patients were functionally demanding with regard to shoulder activities. Three of the five had previously undergone one or more previous rota-

Table 1. Demographic, Clinical Characteristics and Clinical Results

\begin{tabular}{|c|c|c|c|c|c|c|c|c|}
\hline $\begin{array}{c}\text { Patient } \\
\text { no. }\end{array}$ & Sex & Age (yr) & $\begin{array}{c}\text { Follow-up } \\
\text { duration (mo) }\end{array}$ & Occupation & Hobby & Trauma & Site & Previous surgery \\
\hline 1 & Male & 48 & 27.2 & $\begin{array}{l}\text { Member of the national } \\
\text { basketball team }\end{array}$ & Basketball & Ice hockey & Left & $\begin{array}{l}\text { Arthroscopic rotator cuff } \\
\text { repair }\end{array}$ \\
\hline 2 & Male & 57 & 12.0 & Market merchant & Weight training & None & Left & $\begin{array}{l}\text { Arthroscopic rotator cuff } \\
\text { repair }\end{array}$ \\
\hline 3 & Female & 61 & 12.2 & Housewife & - & Slipped down & Right & None \\
\hline 4 & Female & 57 & 24.3 & Housewife & Tennis & None & Right & None \\
\hline 5 & Female & 52 & 24.3 & Housewife & Yoga & None & Right & $\begin{array}{l}\text { Arthroscopic rotator cuff } \\
\text { repair }\end{array}$ \\
\hline
\end{tabular}


tor cuff repair surgeries.

\section{Clinical Outcomes}

Mean postoperative follow-up duration was 20 months (range, 12.0-27.2 months) (Table 1,2) Mean VAS improved significantly from $6.6 \pm 2.6$ (range, $2-8$ ) preoperatively to $1.8 \pm$ 2.5 (range, $0-6)$ postoperatively $(p=0.009)$. Mean ASES score increased from $67.6 \pm 9.2$ (range, 61-80) to $84.6 \pm 15.1$ (range, 57-93), and mean UCLA score from $18.0 \pm 1.4$ (range, 17-20) to $28.8 \pm 8.5$ (range, 13-34) (all $p<0.001$ ) (Table 2, 3). According to UCLA scores 2 patients had an excellent, 2 patients a good, and 1 patient a poor outcome. Active forward elevation improved from a mean of $162^{\circ} \pm 40^{\circ}$ (range, $100^{\circ}-180^{\circ}$ ) to $172^{\circ} \pm 13^{\circ}\left(\right.$ range, $150^{\circ}-180^{\circ}$ ), active external rotation from $14^{\circ}$ $\pm 26^{\circ}\left(\right.$ range, $\left.0^{\circ}-40^{\circ}\right)$ to $31^{\circ} \pm 24^{\circ}\left(\right.$ range, $\left.0^{\circ}-50^{\circ}\right)$, and internal rotation from L2-L3 level to T7-T8; however, no significant differences were found $(p=0.128,0.763$, and 0.339 , respectively; Table 3). No complication, such as hematoma or infection, oc- curred at donor sites, and no patient required revision surgery.

\section{Radiographic Outcome}

Postoperative imaging of the transferred LD tendon showed

Table 3. Clinical Results: VAS, ASES, UCLA Scores and Actives Range of Motion Before and After Surgery

\begin{tabular}{lccr}
\hline \multicolumn{1}{c}{ Variable } & Preoperative & Postoperative & $p$-value \\
\hline VAS & $6.6 \pm 2.6$ & $1.8 \pm 2.5$ & 0.009 \\
ASES score & $67.6 \pm 9.2$ & $84.6 \pm 15.1$ & $<0.001$ \\
\hline UCLA score & $18.0 \pm 1.4$ & $28.8 \pm 8.5$ & $<0.001$ \\
\hline Active forward elevation $\left(^{\circ}\right)$ & $162 \pm 40$ & $172 \pm 13$ & 0.128 \\
\hline Active external rotation $\left(^{\circ}\right)$ & $14 \pm 26$ & $31 \pm 24$ & 0.763 \\
Active internal rotation & L2-L3 level & T7-T8 level & 0.339 \\
\hline
\end{tabular}

Values are presented as mean \pm standard deviation.

VAS: visual analogue scale, ASES: American Shoulder and Elbow Surgeon, UCLA: University of California Los Angeles.

Table 2. Patient VAS, ASES, and UCLA Scores and Active Ranges of Motion Before and After Surgery

\begin{tabular}{|c|c|c|c|c|c|c|c|c|c|c|c|c|c|}
\hline \multirow{2}{*}{$\begin{array}{c}\text { Patient } \\
\text { no. }\end{array}$} & \multicolumn{2}{|c|}{ VAS } & \multicolumn{2}{|c|}{ ASES score } & \multicolumn{2}{|c|}{ UCLA score } & \multicolumn{2}{|c|}{$\begin{array}{l}\text { Active forward } \\
\text { elevation }\left(^{\circ}\right)\end{array}$} & \multicolumn{2}{|c|}{$\begin{array}{l}\text { Active external } \\
\text { rotation }\left({ }^{\circ}\right)\end{array}$} & \multicolumn{2}{|c|}{$\begin{array}{l}\text { Active internal } \\
\text { rotation }\end{array}$} & \multirow{2}{*}{$\begin{array}{l}\text { Post tendon } \\
\text { status }\end{array}$} \\
\hline & Pre & Post & Pre & Post & Pre & Post & Pre & Post & Pre & Post & Pre & Post & \\
\hline 1 & 7 & 0 & 75 & 92 & 19 & 32 & 180 & 180 & 0 & 0 & L3 & $\mathrm{T} 4$ & Intact \\
\hline 2 & 8 & 6 & 61 & 57 & 17 & 13 & 100 & 150 & 0 & 10 & $\mathrm{~L} 4$ & $\mathrm{~T} 12$ & Retear \\
\hline 3 & 8 & 1 & 61 & 93 & 17 & 31 & 180 & 180 & 40 & 50 & $\mathrm{~L} 1$ & $\mathrm{~T} 12$ & Intact \\
\hline 4 & 8 & 2 & 61 & 90 & 17 & 34 & 170 & 170 & 10 & 45 & $\mathrm{~L} 4$ & $\mathrm{~T} 12$ & Intact \\
\hline 5 & 2 & 0 & 80 & 90 & 20 & 34 & 180 & 180 & 20 & 50 & L5 & $\mathrm{T} 12$ & Intact \\
\hline
\end{tabular}

VAS: visual analogue scale, ASES: American Shoulder and Elbow Surgeon, UCLA: University of California Los Angeles, Pre: Preoperative value, Post: Postoperative value.
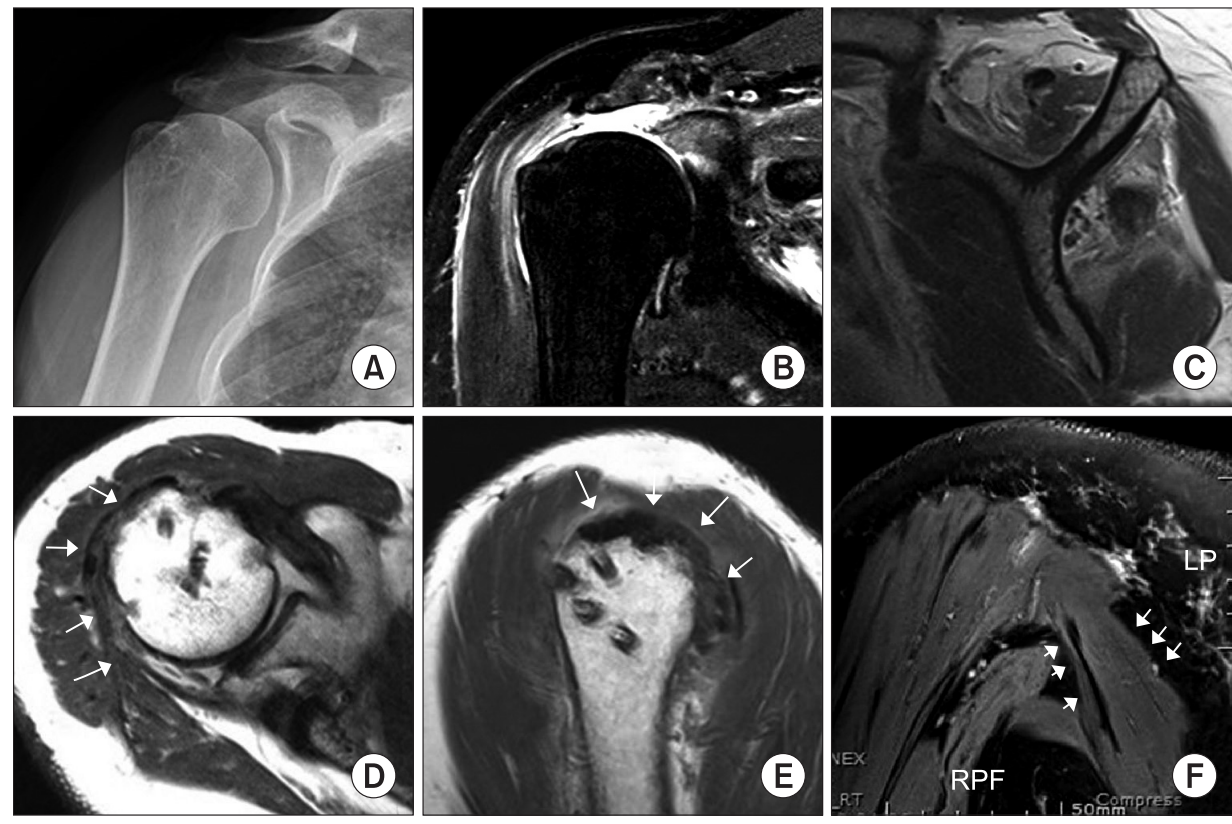

Fig. 2. Arthroscopic-assisted latissimus dorsi (LD) tendon transfer of a 61-year-old female patient in right shoulder. She had no arthritis or superior migration of the humeral head on preoperative simple X-ray (A), while preoperative magnetic resonance imaging (MRI) showed full-thickness rotator cuff tear with retraction, muscle atrophy and fatty infiltration of the supraspinatus and the infraspinatus (B, T2-weighted with fat suppression, coronal image; and C, T1-weighted sagittal oblique image). At 6-months postoperatively, follow-up MRIs shows intact continuity of the transferred latissimus dorsi (LD) tendon (arrows) on the greater tuberosity (D, T2-weighted axial image; E, T2-weighted sagittal oblique image). (F) Notably, transferred LD muscle (arrows) below the deltoid muscle was well-visualized (T2-weighted with fat suppression, coronal oblique image). 
intact repair in 4 patients and rupture in the fifth (Fig. 2). Outcomes of the four patients with intact transfer were rated as excellent or good based on UCLA scores, and outcome in the fifth was rated as poor.

\section{Discussion}

The principal finding of this study was that arthroscopicassisted transfer of the LD tendon provided favorable clinical outcomes in functionally demanding middle-aged patients. At a mean of 20 months postoperatively, all mean outcome measures, including VAS, ASES, and UCLA scores and range of motion had improved. However, small numbers precluded appropriate statistical analysis.

Several limitations of this study should be mentioned. First, it included only five patients. Nevertheless, candidates for surgery were selected using strict criteria, and all patients that underwent surgery were included. No patient was indicated for repair surgery because all five cases were irreparable by our standard arthroscopic technique. Three of the 5 had undergone one or more attempts of rotator cuff repair, and as a result, the risk of failure was of concern to both patient and the surgeon. On the other hand, they were too young and physically active to consider reverse shoulder arthroplasty according to our practice standards. Of the 72 patients with symptomatic massive rotator cuff tear treated during the study period, our patient selection criteria indicated only 5 patients (6.9\%) required arthroscopicassisted LD tendon transfer, which suggests candidates for this surgical technique may be rare. Second, this study had no control group, the mean follow-up was only 20 months, and the study was inherently limited by its retrospective design.

A literature review revealed only four original articles and two technical notes ${ }^{11,12)}$ have reported outcomes after arthroscopicassisted LD transfer and showed its effectiveness for treating massive, irreparable rotator cuff tears (Table 4). ${ }^{8,9,13,14)}$ Castricini et al. ${ }^{9)}$ demonstrated clinical improvements in pain, Constant scores, muscle strength in forward elevation, and range of motion in 27 patients at a mean 27 months postoperatively. In a multicenter series, Grimberg et al. ${ }^{8)}$ reported similarly good outcomes in 55 patients at a mean of 29 months postoperatively. More recently, Yamakado ${ }^{13)}$ also reported good outcomes in 30 patients at 37 months. Kanatlı et al. ${ }^{14)}$ reported outcomes for this technique in patients with pseudoparalysis, and showed significant improvements in active forward elevation from $58^{\circ}$ to $130^{\circ}$ $(p<0.001)$ in 15 patients at a mean 26 months postoperatively, which suggested the technique may be indicated in patients with pseudoparalysis. However, these studies did not address the effect of arthroscopic-assisted LD transfer in relatively young, physically active patients, and included wide age ranges. Mean ages of patients in these previous studies were 60 years or

Table 4. Literature Review of Outcomes After Arthroscopic Assisted Latissimus Dorsi Tendon Transfer for Irreparable Rotator Cuff Tears, and Those of the Current Study

\begin{tabular}{|c|c|c|c|c|c|c|c|}
\hline Author & $\begin{array}{l}\text { Publication } \\
\quad(\mathrm{yr})\end{array}$ & $\begin{array}{l}\text { Case } \\
\text { (n) }\end{array}$ & $\begin{array}{l}\text { Mean length of } \\
\text { follow-up (mo) }\end{array}$ & $\begin{array}{l}\text { Mean age } \\
(\mathrm{yr})\end{array}$ & Clinical result & Radiological result & $\begin{array}{c}\text { Complication or revision } \\
\text { procedure }\end{array}$ \\
\hline $\begin{array}{l}\text { Kanatli } \\
\text { et al. }{ }^{14)}\end{array}$ & 2017 & 15 & 26.4 & $61(52-71)$ & $93.3 \%$ of patients were satisfied & $\begin{array}{l}\text { No data on follow-up } \\
\text { imaging for transferred LD } \\
\text { tendon by MRI, or US }\end{array}$ & None \\
\hline $\begin{array}{l}\text { Grimberg } \\
\text { et al. }{ }^{8}\end{array}$ & 2015 & 55 & 29.4 & $62(31-75)$ & $81.8 \%$ of patients were satisfied & $\begin{array}{l}4 \text { of } 54 \text { patients the LD } \\
\text { tendon was not visible at } \\
\text { 1-year follow-up MRI }\end{array}$ & $\begin{array}{l}9 \% \text { of revision procedure } \\
3 \text { of } 55 \text { patients had } \\
\text { localized hematoma }\end{array}$ \\
\hline $\begin{array}{l}\text { Castricini } \\
\text { et al. }^{9)}\end{array}$ & 2014 & 27 & 27 & $60(46-67)$ & $\begin{array}{l}\text { No data on the percentage of } \\
\text { satisfied patients but mean } \\
\text { Constant and Murley scores, } \\
\text { pain score, muscle strength in } \\
\text { forward elevation, and range } \\
\text { of motion in external rotation } \\
\text { were improved }\end{array}$ & $\begin{array}{l}\text { No data on follow-up } \\
\text { imaging }\end{array}$ & $\begin{array}{l}\text { One wound infection at the } \\
\text { harvest site } \\
11 \% \text { developed a hematoma } \\
\text { at the harvest site }\end{array}$ \\
\hline Yamakado $^{13)}$ & 2017 & 30 & 34 & $67(54-78)$ & $70 \%$ of patients were satisfied & $\begin{array}{l}\text { No data on follow-up } \\
\text { imaging }\end{array}$ & $\begin{array}{l}\text { One hematoma infection at } \\
\text { the harvest site, one deep } \\
\text { infection } \\
\text { One case of transient radial } \\
\text { nerve palsy }\end{array}$ \\
\hline $\begin{array}{l}\text { Current } \\
\text { study }\end{array}$ & $\begin{array}{c}2019 \\
\text { (this study) }\end{array}$ & 5 & 20 & $55(48-61)$ & $\begin{array}{l}80 \% \text { of patients were satisfied as } \\
\text { determined by UCLA scores }\end{array}$ & $\begin{array}{l}\text { In } 1 \text { of the } 5 \text { patients the LD } \\
\text { tendon was ruptured at } 6 \\
\text { months postop by follow- } \\
\text { up MRI }\end{array}$ & $\begin{array}{l}\text { No complication or } \\
\text { revision }\end{array}$ \\
\hline
\end{tabular}

Values are presented as number only, mean only, or median (range).

LD: latissimus dorsi, MRI: magnetic resonance imaging, US: ultrasound, UCLA: University of California Los Angeles. 
older and some of the patients were in their seventies (Table 4), whereas in the current study patients were middle-aged (mean age, 55 years; range, 48-61 years) and physically active. Thus, our patients were more functionally demanding and need better outcomes to perform daily activities and sports. On the other hand, elderly patients with lower functional demands may benefit from only pain relief. Only one of the four studies mentioned above evaluated the integrities of transferred tendons radiographically. In this previous study, Grimberg et al. ${ }^{8)}$ examined transferred tendons by MRI at 1-year surgery and found only 4 ruptured LD tendons among 55 patients (a tendon retear rate of $7.2 \%$ ). Thus, our observation of 4 intact transferred tendons among 5 patients supports the notion that arthroscopic-assisted fixation provides a reliable means of fixing and maintaining the integrity of transferred LD tendons.

However, tendon rupture occurred in one patient. The reasons for this are unclear, though we believe it might be related to fixation technique. Grimberg et al. ${ }^{8)}$ performed arthroscopic-assisted LD tendon fixation with tubularization of the tendon and tendon fixation in a bone tunnel inside the humeral head with an interference screw or with a button on the anterior humeral cortex. In a biomechanical study, tunnel fixation of a tubularized LD tendon with an interference screw was found to be superior to the anchor fixation technique of a flat LD tendon on the greater tuberosity in terms of resistance to traction. ${ }^{15)}$ However, the interference screw technique presents risk of greater tuberosity fracture (incidence $10.5 \%$ ) due to the generation of stress risers during screw insertion. Accordingly, the optimal fixation technique appears to be an issue that requires further study. Traditionally, the open technique has been the standard approach to LD transfer. ${ }^{5,7}$ However, its invasiveness is disadvantageous as it requires detachment of deltoid muscle from the acromion and separate incision on the anterosuperior region of the shoulder in order to secure the harvested LD tendon to the greater tuberosity. On the other hand, repairing the harvested LD tendon without detaching the deltoid muscle is possible using a standard arthroscopic technique. Given that open rotator cuff repair has been largely replaced by arthroscopy due to complications related to the deltoid muscle, the introduction of an arthroscopicassisted technique for LD transfer seems logical. However, it is a technically demanding procedure. A recent study by Yamaka$\mathrm{do}^{13)}$ evaluated the learning curve of this procedure and showed that the learning rate was $84 \%$, which indicates that the necessary operation time for arthroscopic-assisted LD transfer would drop by $16 \%$ when the cumulative volume was doubled, which in practice means, a long learning period is required before surgical times are meaningfully reduced.

\section{Conclusion}

Arthroscopic-assisted LD tendon transfer was found to im- prove shoulder pain and function in patients with massive, irreparable rotator cuff tears, and to be an option for this condition, especially in physically active patients.

\section{References}

1. Longo UG, Lamberti A, Khan WS, Maffulli N, Denaro V. Synthetic augmentation for massive rotator cuff tears. Sports Med Arthrosc Rev. 2011;19(4):360-5. doi: 10.1097/ JSA.0b013e318224e359.

2. Pander P, Sierevelt IN, Pecasse GABM, van Noort A. Irreparable rotator cuff tears: long-term follow-up, five to ten years, of arthroscopic debridement and tenotomy of the long head of the biceps. Int Orthop. 2018;42(11):2633-8. doi: 10.1007/ s00264-018-3991-y.

3. Shon MS, Koh KH, Lim TK, Kim WJ, Kim KC, Yoo JC. Arthroscopic partial repair of irreparable rotator cuff tears: preoperative factors associated with outcome deterioration over 2 years. Am J Sports Med. 2015;43(8):1965-75. doi: 10.1177/0363546515585122.

4. Cho CH, Lee SM, Lee YK, Shin HK. Mini-open suture bridge repair with porcine dermal patch augmentation for massive rotator cuff tear: surgical technique and preliminary results. Clin Orthop Surg. 2014;6(3):329-35. doi: 10.4055/ cios.2014.6.3.329.

5. Gerber C, Rahm SA, Catanzaro S, Farshad M, Moor BK. Latissimus dorsi tendon transfer for treatment of irreparable posterosuperior rotator cuff tears: long-term results at a minimum follow-up of ten years. J Bone Joint Surg Am. 2013;95(21):19206. doi: 10.2106/JBJS.M.00122.

6. Hartzler RU, Burkhart SS. Superior capsular reconstruction. Orthopedics. 2017;40(5):271-80. doi: 10.3928/0147744720170920-02.

7. Gerber C. Latissimus dorsi transfer for the treatment of irreparable tears of the rotator cuff. Clin Orthop Relat Res. 1992;(275):152-60.

8. Grimberg J, Kany J, Valenti P, Amaravathi R, Ramalingam AT. Arthroscopic-assisted latissimus dorsi tendon transfer for irreparable posterosuperior cuff tears. Arthroscopy. 2015;31(4):599607.e1. doi: 10.1016/j.arthro.2014.10.005.

9. Castricini R, Longo UG, De Benedetto M, et al. Arthroscopicassisted latissimus dorsi transfer for the management of irreparable rotator cuff tears: short-term results. J Bone Joint Surg Am. 2014;96(14):e119. doi: 10.2106/JBJS.L.01091.

10. Lo IK, Burkhart SS. The interval slide in continuity: a method of mobilizing the anterosuperior rotator cuff without disrupting the tear margins. Arthroscopy. 2004;20(4):435-41. doi: 10.1016/j.arthro.2004.01.016.

11. Codsi MJ, Hennigan S, Herzog R, et al. Latissimus dorsi tendon transfer for irreparable posterosuperior rotator cuff tears. Surgical technique. J Bone Joint Surg Am. 2007;89 Suppl 2 Pt.1:1- 
9. doi: 10.2106/JBJS.F.01160.

12. Pearle AD, Kelly BT, Voos JE, Chehab EL, Warren RF. Surgical technique and anatomic study of latissimus dorsi and teres major transfers. J Bone Joint Surg Am. 2006;88(7):1524-31. doi: 10.2106/JBJS.E.00426.

13. Yamakado K. Clinical and radiographic outcomes with assessment of the learning curve in arthroscopically assisted latissimus dorsi tendon transfer for irreparable posterosuperior rotator cuff tears. Arthroscopy. 2017;33(12):2144-51. doi: 10.1016/j.arthro.2017.06.015.

14. Kanatlı U, Özer M, Ataoğlu MB, et al. Arthroscopic-assisted latissimus dorsi tendon transfer for massive, irreparable rotator cuff tears: technique and short-term follow-up of patients with pseudoparalysis. Arthroscopy. 2017;33(5):929-37. doi: 10.1016/j.arthro.2016.09.023.

15. Diop A, Maurel N, Chang VK, Kany J, Duranthon LD, Grimberg J. Tendon fixation in arthroscopic latissimus dorsi transfer for irreparable posterosuperior cuff tears: an in vitro biomechanical comparison of interference screw and suture anchors. Clin Biomech (Bristol, Avon). 2011;26(9):904-9. doi: 10.1016/ j.clinbiomech.2011.05.011. 